\title{
Prognostic role of neutrophil-to-lymphocyte ratio in patients with brain arteriovenous malformations
}

\author{
Sunfu Zhang ${ }^{1, *}$, Jing Zhang ${ }^{1, *}$, Qingqing Ren ${ }^{1, *}$, Min $\mathrm{He}^{1, *}$, Baoyin Shan ${ }^{1}$, Yunhui \\ Zeng $^{1}$, Zhiyong Liu ${ }^{1}$, Hao Liu ${ }^{1}$ and Jianguo $X^{1}{ }^{1}$ \\ ${ }^{1}$ Department of Neurosurgery, West China Hospital, West China Medical School, Sichuan University, The First People's \\ Hospital of Yibin, Sichuan, People's Republic of China \\ *These authors contributed equally to this work
}

Correspondence to: Jianguo Xu, email: jgx_2015@163.com

Keywords: brain arteriovenous malformations; cerebral hemorrhage; neutrophils; lymphocytes; prognosis.

Received: March 10, 2017

Accepted: December 05, 2017

Published: January 02, 2018

Copyright: Zhang et al. This is an open-access article distributed under the terms of the Creative Commons Attribution License 3.0 (CC BY 3.0), which permits unrestricted use, distribution, and reproduction in any medium, provided the original author and source are credited.

\section{ABSTRACT}

Purpose: This study was to investigate the prognostic value of the neutrophil-tolymphocyte ratio (NLR) in patients with brain arteriovenous malformations (AVMs).

Materials and Methods: Patients with AVMs were retrospectively identified. A hemogram from peripheral venous blood samples was taken within 24 hours of admission. The occurrences of death or major disability were noted at the end point of 6 months and the outcome was assessed with a modified Rankin Scale score.

Results: A total of 175 patients were enrolled. There were $97(55 \%)$ patients in the ruptured AVMs group and $78(45 \%)$ in the unruptured AVMs group. In patients with unruptured AVMs, NLR was an independent risk factor for poor outcome at 6 months $(p=.036)$, but not a significant predictor with a ROC area of 0.638 . Whereas, NLR was higher in the patients with poor outcome in ruptured AVMs group $(p<.001)$. The area under the curve was $.864(P<.001)$, and an NLR of 8.88 was identified the best discriminating variable and the best predictive cutoff value.

Conclusions: NLR represented a reliable prognostic predictor for patients with ruptured AVMs. However, the NLR could not be a useful prognostic predictor for patients presented with unruptured AVMs.

\section{INTRODUCTION}

Arteriovenous malformations (AVMs) are the most common type of intracranial vascular malformations, and the leading cause of non-traumatic intracerebral hemorrhages in young people less than 35 years old [1]. The incidence of AVMs in unselected population is about 1 per 100,000 per year [2]. AVMs account for $1 \%$ to $2 \%$ of all strokes, $3 \%$ of strokes in young adults, and $9 \%$ subarachnoid hemorrhages, and responsible for $4 \%$ of all primary intracerebral hemorrhages, but as much as one-third in young adults [3]. The annual hemorrhage risk is approximately $1 \%$ for unruptured AVMs, but increases fivefold once ruptured [4-7]. However, the yearly risk of hemorrhage may be as high as $34 \%$ if any additional risk factors such as an aneurysm, deep location, deep drainage and increasing age are present [8].

The mechanisms involved in the growth, progression, and rupture of AVMs are not clearly understood, but studies have shown that inflammation makes a great contribution to their pathogenesis [9]. Activation of several genetic polymorphisms brings about the inflammatory reaction in the AVM walls, which involved in the AVM formation and rupture [10]. Cytokines and proinflammatory factors are secreted followed by inflammatory responses, resulting in increased angiogenesis and various proteinases, which leads to the breakdown of extracellular matrix and cell death, all of which contribute to AVM wall weakening and rupture [11]. Arteriovenous malformation rupture makes intracerebral hemorrhage (ICH) the major cause of AVM-related morbidity and mortality. The inflammatory response contributes to the ICH-induced secondary brain injury although the mechanisms are unknown [12].

Neutrophil-lymphocyte ratio (NLR) is an easy way to evaluate the inflammatory activity in the vascular bed. The aim of this study was to evaluate the relationships 
between the NLR at admission with the 6-month outcome in AVM patients.

\section{RESULTS}

\section{Baseline characteristics}

A cohort of 175 patients was analyzed, who were diagnosed with brain AVMs in our hospital from January to December 2015. Table 1 provides a summary of baseline characteristics of the cohort and differences between the ruptured and unruptured AVMs groups. Overall, 97 patients $(55 \%)$ presented with hemorrhage and 78 patients $(45 \%)$ presented with unruptured AVMs. The mean patient age was $32( \pm 15)$ years, and the mean age of patients with ruptured AVMs was younger than that of unruptured AVMs ( 29 vs. $35, P=.01$ ). The population of our group consisted of $105(60 \%)$ males and $70(40 \%)$ females, giving a male preponderance. The average of AVMs nidus size was 3.5 $( \pm 1.9) \mathrm{cm}$ in diameter. In the patients with ruptured AVMs, presence of deep venous drainage, SM grade (SpetzlerMartin grade), white blood cell (WBC), neutrophil count (Neu) and NLR was higher than those with unruptured AVMs, while lymphocyte count (Lym) lower $(P<.05)$. Furthermore, the deep location of AVMs was remarkably fewer in the unruptured AVMs group than that in the ruptured AVMs group $(P=.03)$, whereas no difference was observed in gender, nidus size, brain eloquence and aneurysm association. Among all the 175 patients, 41 (23\%) received microsurgical resections, and 42 (24\%) had a single Gamma Knife radiation procedure, whereas, only $15(9 \%)$ underwent endovascular embolization of the AVMs. Additionally, 39 (22\%) patients received combinative therapies, while $38(22 \%)$ were conservatively managed. On presentation, $145(83 \%)$ patients had a favorable outcome (mRS score of $0-2)$, and $30(17 \%)$ patients had a poor outcome $(\mathrm{mRS} \geq 3)$. Nevertheless, AVMs resulted in death in $6(3.4 \%)$ patients.

\section{NLR and outcomes of unruptured AVMs}

Of the 78 patients with unruptured AVMs, 73 (94\%) patients had a favorable outcome, and $5(6 \%)$ had a poor outcome (Table 2$)$. The poor outcome patients had larger AVM size $(p=.02)$, higher WBC and neutrophil count ( $p$ $=.003)$, no difference was found in lymphocyte count and $\operatorname{NLR}(P=.68$ and .32 , respectively). Univariable logistic regression analysis identified AVM size $(P=.036)$, WBC $(P=.008)$, neutrophil count $(P=.006)$ and NLR $(P=.044)$ as significant predictors of poor outcome for unruptured AVMs. In multivariate analysis, predictors of poor outcome were AVM size (OR 1.80, 95\% CI 1.01-3.22; $p=.048$ ) and NLR (OR 1.37, 95\% CI 1.02-1.84; $p=.036)$. The area under the ROC curve of NLR was $0.638(<0.70)$, which was not considered a clinically useful predictive factor.

\section{NLR and outcomes of ruptured AVMs}

There were 97 patients presenting with hemorrhage, among whom $72(74 \%)$ patients had a favorable outcome, and $25(26 \%)$ had a poor outcome. The poor outcome (Table 3 ) patients with ruptured AVMs were more inclined to have deep venous drainage $(P=.03)$, eloquence of adjacent brain $(P=.05)$ and higher Spetzler-Martin grades $(P=.004)$. WBC, neutrophil count and NLR were noticeably higher and lymphocyte count lower in the poor outcome patients than that in the favorable outcome patients $(P<.001)$. No difference was found in age, sex, AVM size, intracranial hemorrhage volume, association with aneurysm and locations $(P>.05)$. Univariable logistic regression analysis identified deep venous drainage $(P=.036)$, brain eloquence $(P=.049)$, WBC $(P$ $<.001)$, neutrophil count $(P<.001)$, lymphocyte count $(P<.001)$, NLR $(P=.044)$ and SM grade $(P=.026)$ as significant predictors of poor outcome for ruptured AVMs. In multivariate analysis, predictors of poor outcome were brain eloquence (OR 8.07, 95\% CI 1.96-33.21; $p=.004$ ) and NLR (OR 1.26, 95\% CI 1.14-1.40; $P<.001$ ).

The NLR to predict the poor outcome for patients with ruptured AVMs of the area under the ROC curve was .864 (95\% CI .770-.958; $P<.001)$ (Figure 1). Maximum Youden index was .733, and the optimal cutoff threshold was 8.88 . The sensitivity was .846 , the specificity was .887 , and the accuracy was $80.4 \%$ ( 78 of 97 patients), with a positive predictive value of $60.0 \%$, and a negative predictive value of $89.6 \%$. Meanwhile, the positive likelihood ratio was 7.49 and the negative likelihood ratio was .174 . At 6 months, $60.0 \%$ and $10.4 \%(P<.001)$ of the patients with NLR $\geq 8.88$ and $<8.88$ had a modified Rankin Scale score, $\geq 3$, respectively (OR, 12.86; 95\% CI 4.41-37.51; $P<.001)$.

\section{DISCUSSION}

The major findings of our study were that an NLR 8.88 or higher at admission in patients with ruptured AVMs was independently associated with poor outcome at 6 months, and the NLR represented an available prognostic predictor for patients with ruptured AVMs. However, the NLR could not be a useful prognostic predictor for patients presented with unruptured AVMs, though poor outcome patients showed significantly higher white blood cell and neutrophil count.

Several studies focused on the molecular and cellular biology of brain AVMs have indicated that inflammation plays an important role in the progression and rupture of AVM [11, 13-15]. An inflammatory reaction (cytokines, neutrophils, macrophages, etc.) in the AVM walls is triggered by genetic/ hemodynamic factors upon an inciting event $[10,16]$. Several single-nucleotide polymorphisms have been identified to significantly upregulate the expression of proinflammatory cytokines and angiogenic factors that result in varying levels 
Table 1: Baseline characteristics of all patients and differences between the ruptured and unruptured arteriovenous malformations groups

\begin{tabular}{|c|c|c|c|c|}
\hline & Full Cohort $(n=175)$ & $\begin{array}{l}\text { Ruptured AVMs } \\
\text { Group }(n=97)\end{array}$ & $\begin{array}{c}\text { Unruptured AVMs } \\
\text { Group }(n=78)\end{array}$ & $P$ value \\
\hline Age (years) ${ }^{*}$ & $32 \pm 15$ & $29 \pm 15$ & $35 \pm 15$ & $0.01^{\dagger}$ \\
\hline Gender of Male ${ }^{\#}$ & $105(60)$ & $59(61)$ & $46(59)$ & $0.46^{\ddagger}$ \\
\hline AVM Size $(\mathrm{cm}){ }^{*}$ & $3.5 \pm 1.9$ & $3.7 \pm 2.0$ & $3.2 \pm 1.9$ & $0.12^{\dagger}$ \\
\hline Deep Drainage $^{\#}$ & $82(47)$ & $52(54)$ & $30(38)$ & 0.05 \\
\hline Eloquence $^{\#}$ & $72(41)$ & $38(39)$ & $34(44)$ & $0.56^{\ddagger}$ \\
\hline Spetzler-Martin Grade ${ }^{\#}$ & & & & $0.05^{\ddagger}$ \\
\hline 1 & $28(16)$ & $14(14)$ & $14(18)$ & \\
\hline 2 & $62(35)$ & $32(33)$ & $30(38)$ & \\
\hline 3 & $54(31)$ & $28(29)$ & $26(33)$ & \\
\hline 4 & $24(14)$ & $17(18)$ & $7(9)$ & \\
\hline 5 & $7(4)$ & $6(6)$ & $1(1)$ & \\
\hline Aneurysm Association ${ }^{\#}$ & $15(9)$ & $10(10)$ & $5(6)$ & $0.36^{\ddagger}$ \\
\hline Location $^{\#}$ & & & & $0.03^{\ddagger}$ \\
\hline Lobar & $112(64)$ & $54(56)$ & $58(74)$ & \\
\hline Deep supratentorial & $47(27)$ & $33(34)$ & $14(18)$ & \\
\hline Cerebellar & $16(9)$ & $10(10)$ & $6(8)$ & \\
\hline WBC $(109 / \mathrm{L})^{\$}$ & $6.80(5.53-9.68)$ & $7.75(5.87-13.04)$ & $6.24(5.34-7.40)$ & $<0.001^{\S}$ \\
\hline $\operatorname{Neu}(109 / \mathrm{L})^{\$}$ & $4.18(3.08-7.68)$ & $5.74(3.56-11.23)$ & $3.59(2.87-4.40)$ & $<0.001^{\S}$ \\
\hline $\operatorname{Lym}(109 / \mathrm{L})^{\$}$ & $1.67(1.23-2.08)$ & $1.55(1.05-2.04)$ & $1.78(1.47-2.17)$ & $0.002^{\S}$ \\
\hline $\mathrm{NLR}^{\$}$ & $2.33(1.63-5.82)$ & $3.99(1.76-10.91)$ & $1.91(1.62-2.56)$ & $<0.001^{\S}$ \\
\hline Intervention" & & & & $<0.001^{\ddagger}$ \\
\hline Microsurgery & $41(23)$ & $37(38)$ & $4(5)$ & \\
\hline Radiosurgery & $42(24)$ & $21(22)$ & $21(27)$ & \\
\hline Embolization & $15(9)$ & $5(5)$ & $10(13)$ & \\
\hline Combination & $39(22)$ & $19(20)$ & $20(26)$ & \\
\hline Conservation & $38(22)$ & $15(15)$ & $23(29)$ & \\
\hline
\end{tabular}

AVMs, arteriovenous malformations; WBC, white blood cell; Neu, neutrophil count; Lym, lymphocyte count; NLR, neutrophil-to-lymphocyte ratio. "Data are mean $\pm \mathrm{SD} ;{ }^{*} n(\%) ;{ }^{\mathrm{S}}$ median (interquartile range). "student's $t$-test; "chi-square test; ${ }^{\S}$ Mann-Whitney $U$ test.

of inflammatory responses, which may, in turn, contribute to AVM destabilization and rupture [11]. The overexpression of cell adhesion molecules and endothelial cells induced by the upregulation of proinflammatory cytokines, contributes to enhanced recruitment of leukocytes to the AVM tissue [9]. Neutrophils are primarily located in the inner vessel walls while macrophages in the outer [17-19]. The released cytokines as myeloperoxidase, matrix metalloproteinases, cytokines, and other proteolytic enzymes by recruited leukocytes cause damage to the AVM vessel walls, resulting in rupture of the nidus [20-22]. The upregulation of angiogenic factors affects endothelial cell proliferation, migration and apoptosis, leading to AVM angioarchitecture alterations [23-26]. The effects of inflammation on AVM pathogenesis are potentiated by increased angiogenesis and various proteinases, which cause breakdown of extracellular matrix and cell death, all of which contribute to AVM wall weakening and increased hemorrhagic risk.

Intracranial hemorrhage (ICH) occurs once an AVM ruptured, soon after that inflammatory response is activated. The neutrophils are actively recruited to the ICH injury sites because of the proinflammatory cytokines and chemotactic factors releasing by the activated microglia [12]. Neutrophil infiltration into the site of hemorrhage contributes to brain injury either by direct cellular damage or the recruitment of monocytes, [27]. and neutrophils were highly involved in early neurologic deterioration in ICH patients [28]. Lattanzi et al found that higher neutrophils, lower lymphocytes, and higher NLRs predicted worse 3-month outcome in patients with acute 
Table 2: Demographic, clinical, and laboratory characteristics of the patients with unruptured AVMs according to the 6-month outcome

\begin{tabular}{|c|c|c|c|}
\hline & $\begin{array}{c}\text { Favorable outcome } \\
\qquad(n=73)\end{array}$ & $\begin{array}{l}\text { Poor outcome } \\
\quad(n=5)\end{array}$ & $P$ value \\
\hline Age (years) ${ }^{*}$ & $35 \pm 16$ & $30 \pm 11$ & $0.48^{\dagger}$ \\
\hline Gender of Male ${ }^{\#}$ & $42(58)$ & $4(80)$ & $0.31 \%$ \\
\hline AVM Size $(\mathrm{cm})^{*}$ & $3.1 \pm 1.8$ & $5.1 \pm 1.9$ & $0.02^{\dagger}$ \\
\hline Deep Drainage $^{\#}$ & $28(38)$ & $2(40)$ & 0.64 \\
\hline Eloquence $^{\#}$ & $31(42)$ & $3(60)$ & $0.38^{\ddagger}$ \\
\hline WBC $(109 / \mathrm{L})^{\$}$ & $6.23(5.34-7.30)$ & $8.07(6.45-12.06)$ & $0.03^{\S}$ \\
\hline $\mathrm{Neu}(109 / \mathrm{L})^{\$}$ & $3.47(2.82-4.73)$ & $4.79(3.69-10.94)$ & $0.03^{\S}$ \\
\hline $\operatorname{Lym}(109 / \mathrm{L})^{\$}$ & $1.79(1.47-2.15)$ & $1.71(0.67-2.58)$ & $0.68^{\S}$ \\
\hline $\mathrm{NLR}^{\$}$ & $1.91(1.60-2.49)$ & $1.91(1.71-18.14)$ & $0.32^{\S}$ \\
\hline Aneurysm Association ${ }^{\#}$ & $5(68)$ & $0(0)$ & $0.71^{\ddagger}$ \\
\hline Location & & & $0.36^{\ddagger}$ \\
\hline Lobar $^{\#}$ & $55(75)$ & $3(60)$ & \\
\hline Deep supratentorial ${ }^{\#}$ & $12(16)$ & $2(40)$ & \\
\hline Cerebellar & $6(8)$ & $0(0)$ & \\
\hline Intervention & & & $0.31^{\ddagger}$ \\
\hline Surgery\# & $4(5)$ & $0(0)$ & \\
\hline Radiosurgery\# & $21(29)$ & $0(0)$ & \\
\hline Embolization ${ }^{\#}$ & $8(11)$ & $2(40)$ & \\
\hline Combination $^{\#}$ & $18(25)$ & $2(40)$ & \\
\hline Conservation ${ }^{\#}$ & $22(30)$ & $1(20)$ & \\
\hline
\end{tabular}

AVMs, arteriovenous malformations; WBC, white blood cell; Neu, neutrophil count; Lym, lymphocyte count; NLR, neutrophil-to-lymphocyte ratio. "Data are mean $\pm \mathrm{SD} ;{ }^{*} n(\%) ;{ }^{\$}$ median (interquartile range). "student's $t$-test; ${ }^{*}$ chi-square test; §ann-Whitney $U$ test.

intracerebral hemorrhage [29]. In an observational study enrolled $224 \mathrm{ICH}$ patients, an NLR of 7.35 or higher in patients was significantly higher associated with the mortality than in those with an NLR less than 7.35 [30]. NLR is an established marker of systemic inflammation and is easily calculated [31]. The NLR could represent the inflammatory response to cerebral hematoma and integrate the likelihood of the secondary brain injury and the susceptibility to the post-stroke complications.

To the best of our knowledge, this is the first study to evaluate the association between NLR and outcomes in patients with AVMs. Our data suggested that a higher NLR was significantly associated with poor outcome of patients with ruptured AVMs, but was not a well prognostic predictor for patients with unruptured AVMs.

\section{MATERIALS AND METHODS}

\section{Patient Population and Data Collection}

With the approval of West China Hospital Institutional Review Board, we undertook a retrospective review of our hospital database for all the patients diagnosed of intracranial
AVMs during the period of January 1st, 2015 and December 31st, 2015. The study was allowed to be conducted by the board without patients' consent because of the retrospective study nature. This study will focus only on brain arteriovenous malformations but will not address dural arteriovenous fistulas, cavernous malformations or other vascular malformations in the brain. Patients with other diseases, including neoplasm, autoimmune disease, infectious disease within 6 months, systemic inflammatory disease, trauma, blood system diseases and medication usage related to inflammatory conditions that could significantly influence NLR or prognosis were excluded, as well as those lacking complete data.

A total of 175 patients were identified and patients baseline demographic, clinical, angiographic data were collected. According to the documents, a peripheral venous blood sample was collected at admission within 24 hours, and was used to determine neutrophil and lymphocyte counts, the NLR was then calculated. When a patient was admitted to the hospital, the process of selecting the best therapy included medical conservation, microsurgery, endovascular therapy, and/or radiosurgery was made by a trained cerebrovascular neurosurgeon. As the records displayed, the medical treatment decision was made based 
Table 3: Demographic, clinical, and laboratory characteristics of the patients with ruptured AVMs according to the 6-month outcome

\begin{tabular}{|c|c|c|c|}
\hline & $\begin{array}{l}\text { Favorable } \\
(n=72)\end{array}$ & $\begin{array}{l}\text { Poor Outcome } \\
(n=25)\end{array}$ & $P$ value \\
\hline Age (years) ${ }^{*}$ & $29 \pm 15$ & $28 \pm 12$ & $0.77^{\dagger}$ \\
\hline Gender of Male & $43(60)$ & $16(64)$ & $0.71^{\ddagger}$ \\
\hline AVM Size $(\mathrm{cm})^{*}$ & $3.5 \pm 2.0$ & $4.0 \pm 1.9$ & $0.29^{\dagger}$ \\
\hline Deep Drainage $\mathrm{e}^{\#}$ & $34(47)$ & $18(72)$ & $0.03^{\ddagger}$ \\
\hline Eloquence ${ }^{\#}$ & $24(33)$ & $14(56)$ & $0.05^{\ddagger}$ \\
\hline Spetzler-Martin Grade & & & 0.004 \\
\hline 1 & $12(17)$ & $2(8)$ & \\
\hline 2 & $29(40)$ & $3(12)$ & \\
\hline 3 & $19(26)$ & $9(36)$ & \\
\hline 4 & $8(11)$ & $9(36)$ & \\
\hline 5 & $4(6)$ & $2(8)$ & \\
\hline ICH Volume $(\mathrm{ml}) \$$ & $4.50(1.80-12.68)$ & $6.50(3.86-15.35)$ & $0.29 \S$ \\
\hline Aneurysm Association ${ }^{\#}$ & $6(8)$ & $4(16)$ & $0.28^{\ddagger}$ \\
\hline WBC $(109 / \mathrm{L})^{\$}$ & $7.03(5.59-10.82)$ & $13.11(9.28-17.31)$ & $<0.001^{\text {s }}$ \\
\hline Neu $(109 / \mathrm{L})^{\$}$ & $4.37(3.12-8.66)$ & $11.24(8.16-15.81)$ & $<0.001^{\S}$ \\
\hline $\operatorname{Lym}\left(109 / L^{s}\right.$ & $1.69(1.29-2.11)$ & $0.76(0.64-1.25)$ & $<0.001^{\mathrm{s}}$ \\
\hline $\mathrm{NLR}^{\S}$ & $2.84(1.52-6.75)$ & $13.22(9.57-21.39)$ & $<0.001^{\mathrm{s}}$ \\
\hline Location $^{\#}$ & & & 0.14 \\
\hline Lobar & $44(61)$ & $10(40)$ & \\
\hline Deep supratentorial ${ }^{\#}$ & $21(29)$ & $12(48)$ & \\
\hline Cerebellar & $7(10)$ & $3(12)$ & \\
\hline Intervention ${ }^{\#}$ & & & $0.20^{\ddagger}$ \\
\hline Surgery & $31(43)$ & $6(24)$ & \\
\hline Radiosurgery & $14(19)$ & $7(28)$ & \\
\hline Embolization & $3(4)$ & $2(8)$ & \\
\hline Combination & $12(17)$ & $7(28)$ & \\
\hline Conservation & $12(17)$ & $3(12)$ & \\
\hline
\end{tabular}

AVMs, arteriovenous malformations; ICH, intracranial hemorrhage; WBC, white blood cell; Neu, neutrophil count; Lym, lymphocyte count; NLR, neutrophil-to-lymphocyte ratio. " Data are mean $\pm \mathrm{SD} ;{ }^{*} n$ (\%); ${ }^{\$}$ median (interquartile range). †student's $t$-test; ${ }^{\ddagger}$ chi-square test; ${ }^{\S}$ Mann-Whitney $U$ test.

on both physician recommendations and patient preference. A modified Rankin Scale (mRS) score was assigned to measure the outcome at 6 months, and an mRS score of $0-2$ was considered as a favorable outcome, while an mRS score $\geq 3$ was documented as a poor outcome with the occurrence of death or major disability [32,33].

\section{Statistical analysis}

Statistical analysis was performed with Stata version 14.0 (StataCorp, College Station, Texas). Data was expressed as mean $\pm \mathrm{SD}$, median (interquartile range) or number (\%) of subjects. The difference between 
two groups was tested by Student's $t$-test for normally distributed variables and Mann-Whitney $U$ test for nonparametrically distributed variables. Comparisons for categorical variables were performed with chi-square test or the Fisher exact test. The whole cohort population was divided into two groups, comprising the group of ruptured AVMs and the group of unruptured AVMs, and the statistical analysis was calculated separately based on the two groups. The predictive value of NLR was determined by receiver operating characteristic (ROC) curve test, and the optimal cutoff value was determined by Youden Index. Further odds ratios (ORs) with 95\% confidence intervals (CI) were calculated for a cutoff value of NLR with a binary logistic regression model and multiple logistic regression model. Any $p$ values of $\leq .05$ were considered statistically significant.

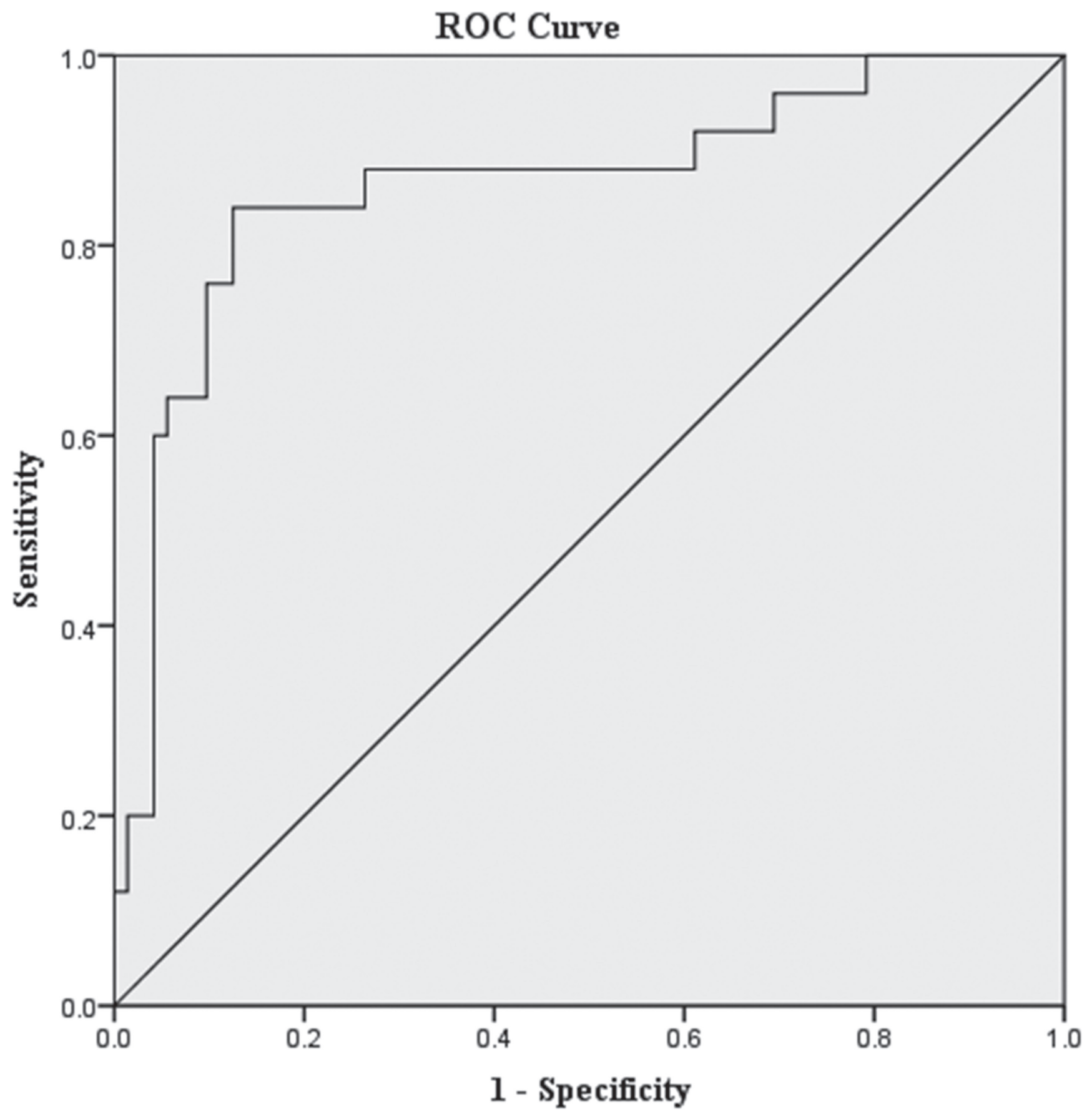

Figure 1: Graph showing receiver operating characteristic analyses of neutrophil-to-lymphocyte ratio for the ruptured arteriovenous malformations. Receiver operating characteristic curves for the 6-mo outcome prediction of ruptured arteriovenous malformations. Predictive values of the neutrophil-to-lymphocyte ratio for the 6-mo poor outcome were considered modified Rankin Scale $\geq 3$. Area under the curve was $.864(95 \%$ confidence interval, .770-.958; $P<.001)$ for NLR. 


\section{CONCLUSIONS}

NLR represented a reliable prognostic predictor for patients with ruptured AVMs, and an NLR 8.88 or higher at admission has an independently predictive value for the poor outcome at 6 months. However, the NLR could not be a useful prognostic predictor for patients presented with unruptured AVMs.

\section{Limitations}

Some limitations of our study should be taken into account. The study is a retrospective review in a singlecenter, with a small sample size. Time-dependent changes of plasma inflammatory biomarkers were found in patients with $\mathrm{ICH}$, suggesting that NLR is a "dynamic" variable. It is not clear that the specific time period at which NLR is a better prognostic biomarker of risk stratification in patients with ruptured AVMs.

\section{Abbreviations}

NLR, the neutrophil-to-lymphocyte ratio; AVMs, brain arteriovenous malformations; mRS, modified Rankin Scale score; OR, odds ratio; CI, confidence intervals; ROC, receiver operating characteristic curve test; ICH, intracerebral hemorrhage; SM, Spetzler-Martin grade; WBC, white blood cell; Neu, neutrophil count; Lym, lymphocyte count.

\section{Author contributions}

Conceptualization: Qingqing Ren, Min He, Jianguo Xu, Data curation: Sunfu Zhang, Jing Zhang, Yunhui Zeng, Formal analysis: Qingqing Ren, Min He, Yunhui Zeng, Funding acquisition: Jianguo $\mathrm{Xu}$, Investigation: Sunfu Zhang, Zhiyong Liu, Methodology: Jing Zhang, Qingqing Ren, Project administration: Jianguo Xu Resources: Sunfu Zhang, Hao Liu, Software: Min He, Zhiyong Liu, Supervision: Jianguo Xu, Validation: Yunhui Zeng, Hao Liu, Visualization: Zhiyong Liu, Writing (original draft preparation): Sunfu Zhang, Qingqing Ren, Writing (review and editing): Hao Liu, Jianguo Xu, Revising: Qingqing Ren, Baoyin Shan, Sunfu Zhang.

\section{CONFLICTS OF INTEREST}

All the authors reported no potential disclosures relevant to the manuscript.

\section{REFERENCES}

1. Ruiz-Sandoval JL, Cantu C, Barinagarrementeria F. Intracerebral hemorrhage in young people: analysis of risk factors, location, causes, and prognosis. Stroke. 1999; 30:537-41.

2. Al-Shahi R, Bhattacharya JJ, Currie DG, Papanastassiou V, Ritchie V, Roberts RC, Sellar RJ, Warlow CP, and Scottish Intracranial Vascular Malformation Study Collaborators. Prospective, population-based detection of intracranial vascular malformations in adults: the Scottish Intracranial Vascular Malformation Study (SIVMS). Stroke. 2003; 34:1163-9. https://doi.org/10.1161/01. str.0000069018.90456.c9.

3. Al-Shahi R, Warlow C. A systematic review of the frequency and prognosis of arteriovenous malformations of the brain in adults. Brain. 2001; 124:1900-26.

4. Kim H, Al-Shahi Salman R, McCulloch CE, Stapf C, Young WL, and MARS Coinvestigators. Untreated brain arteriovenous malformation: patient-level meta-analysis of hemorrhage predictors. Neurology. 2014; 83:590-7. https:// doi.org/10.1212/wnl.0000000000000688.

5. Mohr JP, Parides MK, Stapf C, Moquete E, Moy CS, Overbey JR, Al-Shahi Salman R, Vicaut E, Young WL, Houdart E, Cordonnier C, Stefani MA, Hartmann A, et al, and international ARUBA investigators. Medical management with or without interventional therapy for unruptured brain arteriovenous malformations (ARUBA): a multicentre, nonblinded, randomised trial. Lancet. 2014; 383:614-21. https:// doi.org/10.1016/s0140-6736(13)62302-8.

6. Halim AX, Johnston SC, Singh V, McCulloch CE, Bennett JP, Achrol AS, Sidney S, Young WL. Longitudinal risk of intracranial hemorrhage in patients with arteriovenous malformation of the brain within a defined population. Stroke. 2004; 35:1697-702. https://doi.org/10.1161/01. str.0000130988.44824.29.

7. Hernesniemi JA, Dashti R, Juvela S, Väärt K, Niemelä M, Laakso A. Natural history of brain arteriovenous malformations: a long-term follow-up study of risk of hemorrhage in 238 patients. Neurosurgery. 2008; 63:823-9. https://doi.org/10.1227/01.NEU.0000330401.82582.5E.

8. Stapf C, Mohr JP, Choi JH, Hartmann A, Mast H. Invasive treatment of unruptured brain arteriovenous malformations is experimental therapy. Curr Opin Neurol. 2006; 19:63-8.

9. Mouchtouris N, Jabbour PM, Starke RM, Hasan DM, Zanaty M, Theofanis T, Ding D, Tjoumakaris SI, Dumont AS, Ghobrial GM, Kung D, Rosenwasser RH, Chalouhi N. Biology of cerebral arteriovenous malformations with a focus on inflammation. J Cereb Blood Flow Metab. 2015; 35:167-75. https://doi.org/10.1038/jcbfm.2014.179.

10. Hashimoto T, Lawton MT, Wen G, Yang GY, Chaly T Jr, Stewart CL, Dressman HK, Barbaro NM, Marchuk DA, Young WL. Gene microarray analysis of human brain arteriovenous malformations. Neurosurgery. 2004; 54:410-23; 23-5.

11. Pawlikowska L, Tran MN, Achrol AS, McCulloch CE, Ha C, Lind DL, Hashimoto T, Zaroff J, Lawton MT, Marchuk DA, Kwok PY, Young WL, and UCSF BAVM Study Project. Polymorphisms in genes involved in inflammatory and angiogenic pathways and the risk of hemorrhagic 
presentation of brain arteriovenous malformations. Stroke. 2004; 35:2294-300. https://doi.org/10.1161/01. STR.0000141932.44613.b1.

12. Aronowski J, Zhao X. Molecular pathophysiology of cerebral hemorrhage: secondary brain injury. Stroke. 2011; 42:1781-6. https://doi.org/10.1161/strokeaha.110.596718.

13. Kim H, Pawlikowska L, Chen Y, Su H, Yang GY, Young WL. Brain arteriovenous malformation biology relevant to hemorrhage and implication for therapeutic development. Stroke. 2009; 40:S95-7. https://doi.org/10.1161/ strokeaha.108.533216.

14. Chen Y, Zhu W, Bollen AW, Lawton MT, Barbaro NM, Dowd CF, Hashimoto T, Yang GY, Young WL. Evidence of inflammatory cell involvement in brain arteriovenous malformations. Neurosurgery. 2008; 62:1340-49. https:// doi.org/10.1227/01.neu.0000333306.64683.b5.

15. Guo Y, Saunders T, Su H, Kim H, Akkoc D, Saloner DA, Hetts SW, Hess C, Lawton MT, Bollen AW, Pourmohamad T, McCulloch CE, Tihan T, Young WL, and University of California, San Francisco Brain Arteriovenous Malformation (UCSF bAVM) Study Project. Silent intralesional microhemorrhage as a risk factor for brain arteriovenous malformation rupture. Stroke. 2012; 43:1240-6. https://doi.org/10.1161/strokeaha.111.647263.

16. Lawton MT, Rutledge WC, Kim H, Stapf C, Whitehead KJ, Li DY, Krings T, terBrugge K, Kondziolka D, Morgan MK, Moon K, Spetzler RF. Brain arteriovenous malformations. Nat Rev Dis Primers. 2015; 1:15008. https://doi. org/10.1038/nrdp.2015.8.

17. Rosenberg GA. Growth and bleeding in BAVM: another role for MMPs. Stroke. 2003; 34:925-31. https://doi. org/10.1161/01.str.0000065832.67047.dd.

18. Hashimoto T, Wen G, Lawton MT, Boudreau NJ, Bollen AW, Yang GY, Barbaro NM, Higashida RT, Dowd CF, Halbach VV, Young WL, Rosenberg GA, and University of California, San Francisco BAVM Study Group. Abnormal expression of matrix metalloproteinases and tissue inhibitors of metalloproteinases in brain arteriovenous malformations. Stroke. 2003; 34:925-31. https://doi. org/10.1161/01.str.0000061888.71524.df.

19. Higashi T, Hayashi H, Kaida T, Arima K, Takeyama H, Taki K, Izumi D, Tokunaga R, Kosumi K, Nakagawa S, Okabe H, Imai K, Nitta H, et al. Prognostic Impact of Visceral Fat Amount and Branched-Chain Amino Acids (BCAA) in Hepatocellular Carcinoma. Ann Surg Oncol. 2015; 22:S1041-7. https://doi.org/10.1245/s10434-015-4796-5.

20. Rosenberg GA. Matrix metalloproteinases in neuroinflammation. Glia. 2002; 39:279-91. https:/doi. org/10.1002/glia.10108.

21. Li X, Wang R, Wang X, Xue X, Ran D, Wang S. Relevance of IL-6 and MMP-9 to cerebral arteriovenous malformation and hemorrhage. Mol Med Rep. 2013; 7:1261-6. https:// doi.org/10.3892/mmr.2013.1332.

22. Chen Y, Fan Y, Poon KY, Achrol AS, Lawton MT, Zhu Y, McCulloch CE, Hashimoto T, Lee C, Barbaro NM,
Bollen AW, Yang GY, Young WL. MMP-9 expression is associated with leukocytic but not endothelial markers in brain arteriovenous malformations. Front Biosci. 2006; $11: 3121-8$.

23. Sturiale CL, Puca A, Sebastiani P, Gatto I, Albanese A, Di Rocco C, Maira G, Pola R. Single nucleotide polymorphisms associated with sporadic brain arteriovenous malformations: where do we stand? Brain. 2013; 136:66581. https://doi.org/10.1093/brain/aws180.

24. Kim H, Hysi PG, Pawlikowska L, Poon A, Burchard EG, Zaroff JG, Sidney S, Ko NU, Achrol AS, Lawton MT, McCulloch CE, Kwok PY, Young WL. Common variants in interleukin-1-Beta gene are associated with intracranial hemorrhage and susceptibility to brain arteriovenous malformation. Cerebrovasc Dis. 2009; 27:176-82. https:// doi.org/10.1159/000185609.

25. Fontanella M, Rubino E, Crobeddu E, Gallone S, Gentile S, Garbossa D, Ducati A, Pinessi L, Rainero I. Brain arteriovenous malformations are associated with interleukin-1 cluster gene polymorphisms. Neurosurgery. 2012; 70:12-7. https://doi.org/10.1227/ NEU.0b013e31822d9881.

26. Hashimoto T, Wu Y, Lawton MT, Yang GY, Barbaro NM, Young WL. Coexpression of angiogenic factors in brain arteriovenous malformations. Neurosurgery. 2005; 56:1058-65.

27. Sansing LH, Harris TH, Kasner SE, Hunter CA, Kariko K. Neutrophil depletion diminishes monocyte infiltration and improves functional outcome after experimental intracerebral hemorrhage. Acta Neurochir Suppl. 2011; 111:173-8. https://doi.org/10.1007/978-3-7091-0693-8_29.

28. Leira R, Dávalos A, Silva Y, Gil-Peralta A, Tejada J, Garcia M, Castillo J, and Stroke Project, Cerebrovascular Diseases Group of the Spanish Neurological Society. Early neurologic deterioration in intracerebral hemorrhage: predictors and associated factors. Neurology. 2004; 63:461-7.

29. Lattanzi S, Cagnetti C, Provinciali L, Silvestrini M. Neutrophil-to-Lymphocyte Ratio Predicts the Outcome of Acute Intracerebral Hemorrhage. Stroke. 2016; 47:1654-7. https://doi.org/10.1161/strokeaha.116.013627.

30. Wang F, Hu S, Ding Y, Ju X, Wang L, Lu Q, Wu X. Neutrophil-to-Lymphocyte Ratio and 30-Day Mortality in Patients with Acute Intracerebral Hemorrhage. J Stroke Cerebrovasc Dis. 2016; 25:182-7. https://doi.org/10.1016/j. jstrokecerebrovasdis.2015.09.013.

31. Zahorec R. Ratio of neutrophil to lymphocyte counts--rapid and simple parameter of systemic inflammation and stress in critically ill. Bratisl Lek Listy. 2001; 102:5-14.

32. van Swieten JC, Koudstaal PJ, Visser MC, Schouten HJ, van Gijn J. Interobserver agreement for the assessment of handicap in stroke patients. Stroke. 1988; 19:604-7.

33. Weisscher N, Vermeulen M, Roos YB, de Haan RJ. What should be defined as good outcome in stroke trials; a modified Rankin score of $0-1$ or $0-2$ ? J Neurol. 2008; 255:867-74. https://doi.org/10.1007/s00415-008-0796-8. 